\title{
Transparent Sol-Gel Oxyfluoride Glass-Ceramics with High Crystalline Fraction and Study of RE Incorporation
}

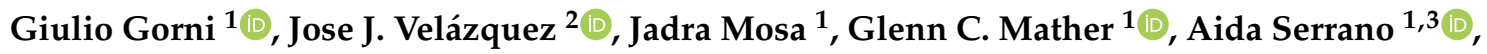 \\ María Vila ${ }^{3,4}$, Germán R. Castro ${ }^{3,4}$, David Bravo ${ }^{5}$, Rolindes Balda ${ }^{6,7} \odot$, Joaquín Fernández ${ }^{8}$, \\ Alicia Durán ${ }^{1}$ and Yolanda Castro ${ }^{1, *}$ (i) \\ 1 Instituto de Cerámica y Vidrio, CSIC, 28049 Madrid, Spain; ggorni@icv.csic.es (G.G.); jmosa@icv.csic.es (J.M.); \\ mather@icv.csic.es (G.C.M.); aida.serrano@icv.csic.es (A.S.); aduran@icv.csic.es (A.D.) \\ 2 FunGlass-Centre for Functional and Surface Functionalized Glass, Alexander Dubček University of \\ Trenčín, Trenčín 91150, Slovakia; jose.velazquez@tnuni.sk \\ 3 SpLine, Spanish CRG Beamline-European Synchrotron Radiation Facility (ESRF), 38043 Grenoble, France; \\ maria.vila-santos@esrf.fr (M.V.); german.castro@esrf.fr (G.R.C.) \\ 4 Instituto de Ciencia de Materiales de Madrid, CSIC, 28049 Madrid, Spain \\ 5 Departamento Física de Materiales, Facultad de Ciencias, Universidad Autónoma de Madrid (UAM), \\ 28049 Madrid, Spain; david.bravo@uam.es \\ 6 Departamento Física Aplica I, Escuela Superior de Ingeniería, Universidad del País Vasco (UPV-EHU), \\ 48013 Bilbao, Spain; rolindes.balda@ehu.eus \\ 7 Centro de Física de Materiales, (UPV/EHU-CSIC), 20018 San Sebastian, Spain \\ 8 Donostia International Physics Center (DIPC), 20018 San Sebastian, Spain; xuaco@dipc.org \\ * Correspondence: castro@icv.csic.es; Tel.: +34-917-355-840
}

Received: 28 February 2019; Accepted: 26 March 2019; Published: 3 April 2019

check for updates

\begin{abstract}
Transparent oxyfluoride glass-ceramic films and self-supported layers with composition $80 \mathrm{SiO}_{2}-20 \mathrm{LaF}_{3}$ doped with $\mathrm{Er}^{3+}$ have been successfully synthesized by sol-gel process for the first time. Crack-free films and self-supported layer with a maximum thickness up to $1.4 \mu \mathrm{m}$ were obtained after heat treatment at the low temperature of $550{ }^{\circ} \mathrm{C}$ for $1 \mathrm{~min}$, resulting in a $\mathrm{LaF}_{3} \mathrm{crystal}$ fraction of $18 w t \%$, as confirmed by quantitative Rietveld refinement. This is the highest value reported up to now for transparent oxyfluoride glass-ceramics prepared by sol-gel. This work provides a new synthesis strategy and opens the way to a wide range of potential applications of oxyfluoride glass-ceramics. The characterization by a wide range of techniques revealed the homogeneous precipitation of $\mathrm{LaF}_{3}$ nanocrystals into the glass matrix. X-ray absorption spectroscopy and electron paramagnetic resonance confirmed that the $\mathrm{Er}^{3+}$ ions are preferentially embedded in the low phonon-energy $\mathrm{LaF}_{3}$ nanocrystals. Moreover, photoluminescence (PL) measurements confirmed the incorporation of dopants in the $\mathrm{LaF}_{3}$ nanocrystals. The effective concentration of rare-earth ions in the $\mathrm{LaF}_{3}$ nanocrystals is also estimated by X-ray absorption spectroscopy.
\end{abstract}

Keywords: glass-ceramic; oxyfluoride; rare-earth; crystallization; sol-gel

\section{Introduction}

Oxyfluoride glass-ceramics (OxGCs) have attracted great interest in the field of photonics since the pioneering work of Wang and Ohwaki [1]. OxGCs are polycrystalline materials containing fluoride nano-crystals (NCs) that crystallize in a glass matrix during a controlled heat treatment of the precursor glass. Alumina-silicate glass matrices are suitable, due to their excellent mechanical, thermal and chemical properties compared to phosphate or fluoride glasses. In addition, OxGCs may host 
Rare-Earth (RE) ions in the low-phonon energy fluoride crystals $\left(300-450 \mathrm{~cm}^{-1}\right)$, thereby increasing the luminescence efficiency with respect to the corresponding oxide glasses [2-14]. The melt-quenching (MQ) method has been routinely used to prepare OxGCs that showed excellent optical properties and a significant enhancement of photoluminescence with respect to the precursor glasses. Moreover, the possibility to draw fibers and convert the core into a GC revealed the importance of this method for the preparation of novel devices with new or improved optical efficiencies [15-20]. However, the high melting temperatures $\left(1400-1700{ }^{\circ} \mathrm{C}\right)$ greatly affect the fluoride content, limiting the crystal phase content to $10 \mathrm{wt} \%$ or less for some crystal phases, such as $\mathrm{LaF}_{3}[7,9,10]$. Furthermore, phase separation and spontaneous fluoride crystallization are usually present, due to fluorine immiscibility at high temperature in oxide-glass matrices. For these reasons, this method still has to overcome some problems and efforts are required to improve the quality and processing of these materials. Another crucial point concerns the incorporation of dopants into the fluoride NCs. In fact, it is known that in melted glasses there is a portion of RE ions that remain outside the fluoride NCs even after heat treatment for prolonged periods [10,12]. This phenomenon is explained considering the high glass viscosity at typical crystallization temperatures $\left(T_{\mathrm{g}}+20-100^{\circ} \mathrm{C}\right)$ that limits ionic diffusion. Moreover, due to the depletion of crystal formers in the glass matrix, a viscous Si-enriched shell forms around the crystals, which further limits ionic diffusion. A challenging goal is to obtain homogeneous materials with much higher fluoride contents and with higher dopant incorporation in the NCs, thus improving the optical efficiency.

The sol-gel (SG) route appears to be a promising alternative to prepare OxGC films and bulk materials for different applications, such as planar waveguides or integrated optics [21-36]. Ballato et al. [35] proposed to use $\mathrm{LaF}_{3}$ into planar photonic devices, such as planar confined waveguide and Kumar et al. [36] described $\mathrm{Er}^{3+}$ doped $\mathrm{LaF}_{3}$ transparent gels for its use in the infrared (IR) waveguide amplifiers at $1.5 \mu \mathrm{m}$.

The SG process is a cheap and extremely flexible chemical method for obtaining pure and very homogenous materials, as well as offering a wide range of possible nano/micro-structures at relatively low sintering temperatures $\left(100-600{ }^{\circ} \mathrm{C}\right)$. Synthesis classically involves the hydrolysis and polycondensation of metal salts or metal-organic precursors, such as tetraethyl orthosilicate (TEOS), in alcoholic media [37]. In the late nineties, Fujihara et al. prepared the first OxGC SG materials in a two-step process [21] involving preparation of silica sol using the classical route followed by mixing of fluoride and RE-ion precursors (acetates, nitrates, chlorides etc.) dissolved in ethanol or acidic medium. The mixing of both solutions, with subsequent controlled crystallization, leads to the precipitation of fluoride crystals in the silica-glass matrix. However, the literature mostly describes the preparation of OxGC materials with a nominal content of $5 \mathrm{~mol} \%$ active crystal phase, and with the final crystal fraction not being estimated [38]. For example, Szpikowska-Sroka reported $3 \mathrm{wt} \%$ of the crystallized phase for a nominal concentration of $5 \mathrm{~mol} \%$ [34] Such concentrations are even lower than those obtained by MQ [2,10,12]. Other authors have attempted to increase the crystal content up to $15 \mathrm{~mol} \%$ but opaque materials were obtained [21]. Moreover, high treatment temperatures $\left(800-1000{ }^{\circ} \mathrm{C}\right)$ are used to obtain OxGCs from the amorphous precursors, even though the typical crystallization temperature of fluorides is between $280-350{ }^{\circ} \mathrm{C}$. To date, the use of sol-gel to obtain OxGCs has not been widely investigated because no significant improvement in structural and optical properties has been achieved since the earliest papers. There is still much work to be performed on correlating the crystallization mechanism of these materials with the structure, dopant incorporation and optical properties.

In this work, novel OxGC materials with a much higher active crystal phase content and sintered at a much lower temperature than previously reported have been prepared by taking advantage of the particular benefits of the SG process. In addition, it was demonstrated how this method leads to precipitation of RE-doped NCs using short heat treatment times. Moreover, it is shown how most RE ions are incorporated into the NCs during the crystallization process. 


\section{Materials and Methods}

\subsection{Materials Preparation}

Sols of composition (mol\%) $80 \mathrm{SiO}_{2}-20 \mathrm{LaF}_{3}$ doped with 0.1 and $0.5 \mathrm{Er}^{3+}$ were prepared by partially replacing TEOS (Sigma Aldrich, St. Louis, MO, USA) with methyl-trimethoxy-silane (MTES, abcr, Karlsruhe, Germany) as a precursor with a TEOS/MTES molar ratio of 40/60. The synthesis was performed in two- step process starting from a silica sol with molar ratio: 0.4TEOS:0.6MTES:2.5 $\mathrm{CH}_{3} \mathrm{CH}_{2} \mathrm{OH}: 1 \mathrm{H}_{2} \mathrm{O}(0.1 \mathrm{HCl}): 0.2 \mathrm{CH}_{3} \mathrm{COOH}$ (Merck, Darmstadt, Germany) stirred for $2 \mathrm{~h}$ at room temperature. Subsequently, $\mathrm{La}\left(\mathrm{CH}_{3} \mathrm{COO}\right)_{3}$ (Sigma Aldrich), ethanol (EtOH), $\mathrm{H}_{2} \mathrm{O}$ and trifluoroacetic acid (TFA, Sigma Aldrich) in the molar ratio 1:5:4:4 was stirred for $2 \mathrm{~h}$ at $40{ }^{\circ} \mathrm{C}$ and then mixed with the silica sol in the ratio 0.8(TEOS + MTES):0.2La.

Thin films on silica and silicon wafers (111) were prepared by dip coating using withdrawal rates of $10-35 \mathrm{~cm} / \mathrm{min}$. Finally, the films were treated at $550^{\circ} \mathrm{C}$ for $1 \mathrm{~min}$ and $1 \mathrm{~h}$ using a heating rate of $10{ }^{\circ} \mathrm{C} / \mathrm{min}$.

Moreover, self-supported layers (bulk-like monoliths 1-2 mm thick) of $80 \mathrm{SiO}_{2}-20 \mathrm{LaF}_{3}$ composition doped with 0.1 and $0.5 \mathrm{Er}^{3+}$ were prepared with TEOS and TEOS-MTES using the molar ratio 1TEOS:3EtOH:2 $\mathrm{H}_{2} \mathrm{O}(0.1 \mathrm{HCl})$ and 0.4TEOS:0.6MTES:3EtOH:2 $\mathrm{H}_{2} \mathrm{O}(0.1 \mathrm{HCl})$, respectively. An acetate dissolution, similar to that used for thin films, was added, raising the $\mathrm{H}_{2} \mathrm{O}$ content to obtain a total molar ratio 1 TEOS: $10 \mathrm{H}_{2} \mathrm{O}$ or 1 (TEOS+MTES): $10 \mathrm{H}_{2} \mathrm{O}$.

Then, the sol was deposited into Petri dishes, covered, sealed and kept at $50{ }^{\circ} \mathrm{C}$ for 1 week to obtain the xerogel samples. GC samples were obtained by heating the xerogels at $550{ }^{\circ} \mathrm{C}$ for $1 \mathrm{~min}$ up to $1 \mathrm{~h}$, with an intermediate step at $150{ }^{\circ} \mathrm{C}$ to remove water and solvents. Samples prepared with only TEOS were treated up to $650^{\circ} \mathrm{C}$ for $1 \mathrm{~h}$ using a heating rate of $1^{\circ} \mathrm{C} / \mathrm{min}$. The samples will be labelled with the composition followed by the silica precursor used for their preparation (TEOS) or (TEOS-MTES).

\subsection{Characterization of Coatings and Self-supported Layers}

Thin films deposited onto a silica and silicon wafer were characterized by spectroscopic ellipsometry in the range 250-1000 nm using an M-2000UTM ellipsometer (J.A. Woollam Co., Lincoln, NE, USA). The incident angles were set to $50^{\circ}$ and $60^{\circ}$ and the acquisition time to $10 \mathrm{~s}$. The data were fitted using the CompleteEASE software (version 5.20, J.A. Woollam Co.) representing the film as a Cauchy layer deposited onto the corresponding substrate.

Differential thermal analysis (DTA) and thermogravimetry (TG) were measured using the SDT Q600 instrument (TA Instruments, New Castle, DE, USA). Around 20-30 mg of powder materials with a size of $1-1.25 \mathrm{~mm}$, obtained after drying the sol at $50{ }^{\circ} \mathrm{C}$, were measured in air and Argon using a heating rate of $10^{\circ} \mathrm{C} / \mathrm{min}$.

X-Ray diffraction (XRD) patterns of $80 \mathrm{SiO}_{2}-20 \mathrm{LaF}_{3}-0.5 \mathrm{Er}^{3+}$ self-supported layers and grazing incidence XRD (GI-XRD) of $80 \mathrm{SiO}_{2}-20 \mathrm{LaF}_{3}$ thin films were obtained at the BM25B-SpLine beamline of the ESRF (European Synchrotron Radiation Facility, Grenoble, France) [39], using an X-ray wavelength of $0.619 \AA$. For GI-XRD measurements, an incidence angle of $0.5^{\circ}$ was used. The crystal size, $\phi$, was estimated using the Scherrer's equation:

$$
\phi=\frac{0.94 \lambda}{\cos \theta \sqrt{B_{m}^{2}-B_{i}^{2}}}
$$

where $\lambda$ is the wavelength, $B_{m}$ the full width half maximum of the peak and $\theta$ its diffraction angle. The instrumental broadening $B_{i}$ was also taken into account. The diffraction-peak parameters were fit using a pseudo Voigt function.

Rietveld Refinement was performed using the FullProf software (FullProf Suite July 2017) [40], and the $\mathrm{LaF}_{3}$ crystal fraction was estimated using $\mathrm{NaF}$ as the internal weight standard in a similar 
manner to that described previously [12]. X-ray powder data were collected over the range $20^{\circ} \leq 2 \theta \leq$ $120^{\circ}$ in a step width of $0.0289^{\circ}$ and a counting time of 4 s per step employing a Bruker D8 high-resolution diffractometer (BRUKER, Billerica, MA, USA) equipped with a solid-state rapid LynxEye detector, and monochromatic $\mathrm{Cu} \mathrm{K} \alpha 1$ radiation.

High Resolution Transmission Electron Microscopy (HRTEM) was performed using a JEOL 2100 field emission gun (Akishima, Tokyo, Japan) operating at $200 \mathrm{kV}$ with a point resolution of $0.19 \mathrm{~nm}$. The samples were obtained by scratching the films or milling the self-supported layers and dispersing in $\mathrm{EtOH}$. Then, one or two drops of suspensions were depositing on the scaled fragments onto carbon-coated copper grids. The solvent was removed after drying the copper grids under a UV lamp.

$\mathrm{Er}^{3+} \mathrm{L}_{3}$ edge X-Ray absorption spectroscopy (XAS, Grenoble, France) were used to characterize the $80 \mathrm{SiO}_{2}-20 \mathrm{LaF}_{3} 0.5 \mathrm{Er}^{3+}$ films treated at $150{ }^{\circ} \mathrm{C}$ for $1 \mathrm{~h}$ (xerogel) and at $550{ }^{\circ} \mathrm{C}$ for $1 \mathrm{~min}$ (GC) employing the BM25A-SpLine beamline (ESRF, Grenoble, France). XAS measurements were collected in fluorescence mode using a 13 element $\mathrm{Si}(\mathrm{Li})$ solid-state detector with the sample surface placed at an angle of $45^{\circ}$ to the incident beam. The spectra represent an average of at least six scans; the XAS data were processed using the software ATHENA (Demeter 0.9.26) [41]. Both $\operatorname{ErF}_{3}$ and $\operatorname{Er}_{2} \mathrm{O}_{3}$ standards were also measured as references.

Electron Paramagnetic Resonance (EPR) spectra were obtained by a Bruker ESP 300E spectrometer (BRUKER) working in the X-band with field modulation of $100 \mathrm{kHz}$. The temperature was controlled with a continuous-flow helium cryostat ESR 900 (Oxford Instruments, Abingdon, UK) and the calibration of the resonance magnetic fields and microwave frequencies measured with an NMR Gauss-meter ER 035 M (BRUKER) and a frequency meter (Hewlett-Packard 5342A, Palo Alto, CA, USA), respectively. Self-supported layer samples (xerogel and GCs) doped with 0.1 and $0.5 \mathrm{Er}^{3+}$ were milled and rolled in Teflon tape to perform the measurements.

The steady-state emission spectra were performed by exciting the $80 \mathrm{SiO}_{2}-20 \mathrm{LaF}_{3}$ bulk samples and thin films doped with 0.1 and $0.5 \mathrm{Er}^{3+}$ with a tunable Ti-sapphire ring laser $\left(0.4 \mathrm{~cm}^{-1}\right.$ linewidth) in the 770-920 nm spectral range. The fluorescence was analyzed with a $0.25 \mathrm{~m}$ monochromator, and the signal was detected by an extended IR Hamamatsu H10330A-75 photomultiplier (Hamamatsu, Shizuoka, Japan) and finally amplified by a standard lock-in technique. The sample temperature was varied between 9 and $300 \mathrm{~K}$ in a continuous flow cryostat.

Lifetime measurements were obtained by exciting the $80 \mathrm{SiO}_{2}-20 \mathrm{LaF}_{3}-0.1 \mathrm{Er}^{3+}$ (TEOS) bulk sample treated at $650{ }^{\circ} \mathrm{C}$ for $1 \mathrm{~h}$ with a Ti-sapphire laser pumped by a pulsed frequency-doubled Nd:YAG laser, 9 ns pulse width, (BM Industries, Paris, France), and detecting the emission with Hamamatsu H10330A-75 photomultiplier. Data were processed by a Tektronix oscilloscope (Tektronix Inc., Beaverton, OR, USA).

\section{Results and Discussion}

\subsection{Self-supported Layers and Thin Films}

Crack-free and homogeneous self-supported layers were obtained before and after heat treatment of the doped and undoped $80 \mathrm{SiO}_{2}-20 \mathrm{LaF}_{3}$ samples at $550{ }^{\circ} \mathrm{C}$ for $1 \mathrm{~min}$, Figure 1.

Homogeneous and transparent films with good adhesion were obtained for all the withdrawal rates used. The good agreement between measurement and fitted data, Figure $2 \mathrm{a}$, demonstrated the good quality of the films. The inset of Figure 2a shows the variation of the refractive index as a function of the wavelength in the transparent region of the sample. The corresponding thickness varies almost linearly with the withdrawal rate, up to a thickness of $\sim 1.4 \mu \mathrm{m}$ in a single deposition and using a withdrawal rate of $35 \mathrm{~cm} / \mathrm{min}$, Figure $2 \mathrm{~b}$. The addition of MTES allows the thickness of films to be increased, compared to when only TEOS is used. In particular, according to [42], the TEOS/MTES ratio $0.4 / 0.6$ produces the highest critical thickness. Moreover, the addition of MTES improves the mechanical strength of the self-supported layers. Such behavior is associated with the presence of 
$\mathrm{CH}_{3}$ groups which allow the porosity to be increased in the silica network reducing the stress [42]. The amount of $\mathrm{OH}$ groups is also reduced when MTES is added to TEOS because the surfaces become more hydrophobic [42,43].
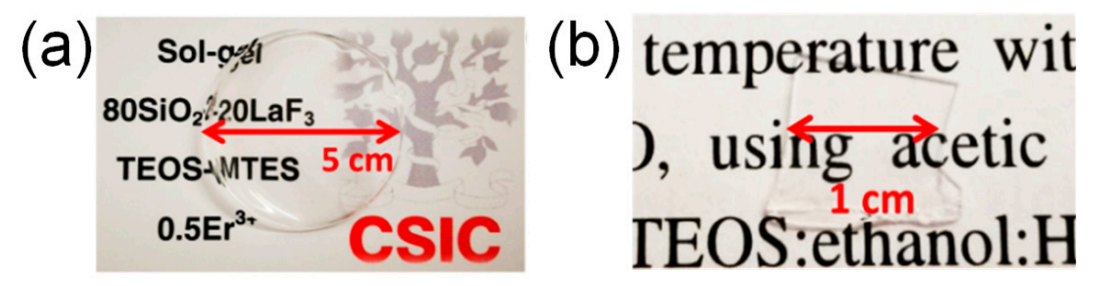

Figure 1. (a) Xerogel of composition $80 \mathrm{SiO}_{2}-20 \mathrm{LaF}_{3}-0.5 \mathrm{Er}^{3+}$ (tetraethyl orthosilicate with methyltrimethoxy-silane, TEOS-MTES) obtained at $150^{\circ} \mathrm{C}$ for $24 \mathrm{~h}$; (b) Oxyfluoride glass-ceramics (OxGC) of the same composition obtained at $550{ }^{\circ} \mathrm{C}$ for $1 \mathrm{~min}$.
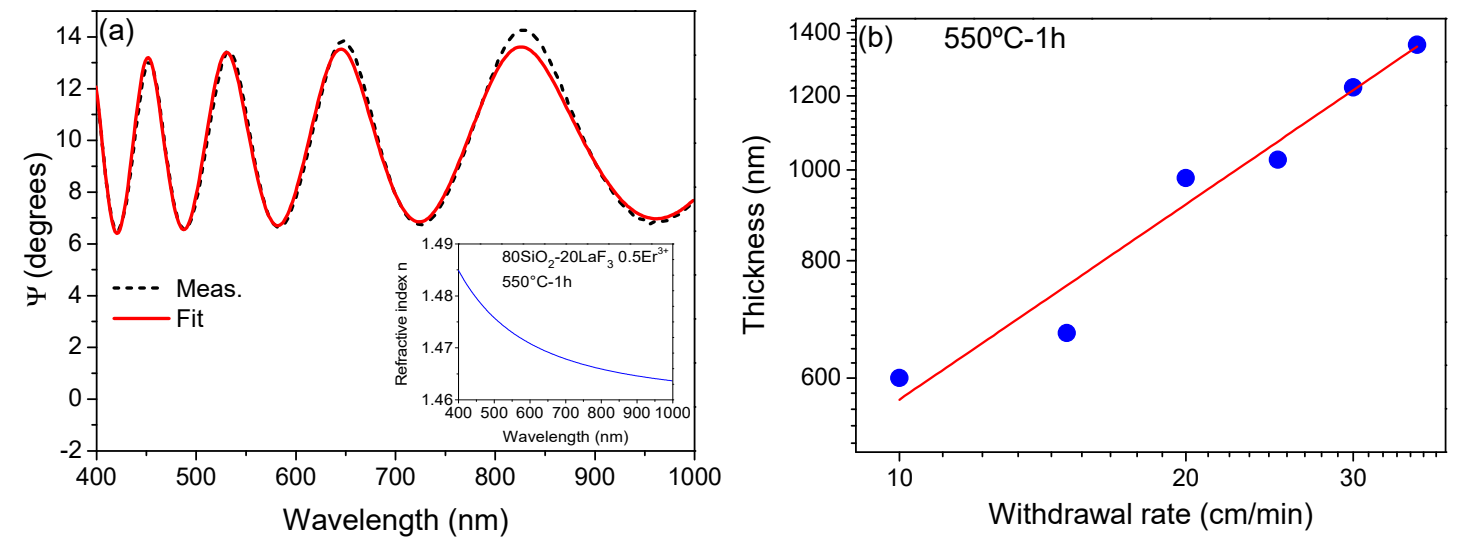

Figure 2. (a) Ellipsometric measurements and fit of $80 \mathrm{SiO}_{2}-20 \mathrm{LaF}_{3}-0.5 \mathrm{Er}^{3+}$ (TEOS-MTES) thin film treated at $550{ }^{\circ} \mathrm{C}$ for $1 \mathrm{~min}$ deposited onto silica substrate using a withdrawal rate of $35 \mathrm{~cm} / \mathrm{min}$. The inset shows the dispersion relation using the Cauchy model (b) Variation of thickness with the withdrawal rate.

\subsection{DTA and Crystallization}

Figure 3 shows a DTA curve for self-supported layers measured in air with a heating rate of $10{ }^{\circ} \mathrm{C} / \mathrm{min}$. The endothermic process at $\sim 100{ }^{\circ} \mathrm{C}$ corresponds to water and solvent removal. The first sharp exothermic peak at $\sim 280{ }^{\circ} \mathrm{C}$ is associated with $\mathrm{LaF}_{3}$ crystallization and the corresponding mass loss $(\sim 30 \%)$ is due to decomposition reactions, as studied elsewhere [44]. The sharpness of the crystallization peak means that the process occurs very rapidly; in contrast, the $\mathrm{LaF}_{3}$ crystallization peak in the melted glasses is much broader and less intense [12]. Moreover, the $T_{\mathrm{g}}$ of these samples is higher than $1000{ }^{\circ} \mathrm{C}$, as reported in a previous paper [44], and the crystallization of SG OxGCs occurs at much lower temperature than the $T_{\mathrm{g}}$. The crystallization mechanism is, thus, clearly different with respect to that of MQ OxGCs [45-49]. The second exothermic process at $\sim 575{ }^{\circ} \mathrm{C}$, associated with oxidation of $\mathrm{CH}_{3}$ groups with a further mass loss of around $10 \%$, does not appear in $\mathrm{Ar}$ atmosphere. Heat treatment at temperatures higher than that of $\mathrm{CH}_{3}$ elimination causes a sudden shrink of films and self-supported layers, leading to crack of the samples. 


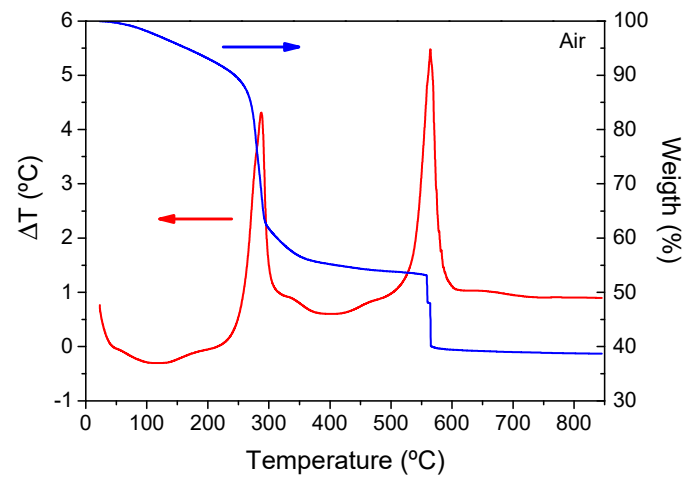

Figure 3. Differential thermal analysis (DTA, red) and thermogravimetry (TG, blue) curve for $80 \mathrm{SiO}_{2}-20 \mathrm{LaF}_{3}-0.5 \mathrm{Er}^{3+}$ (TEOS-MTES) bulk sample treated in the air with a heating rate of $10{ }^{\circ} \mathrm{C} / \mathrm{min}$.

\subsection{XRD, GI-XRD and Crystal Fraction}

The XRD of $80 \mathrm{SiO}_{2}-20 \mathrm{LaF}_{3}-0.1 \mathrm{Er}^{3+}$ (TEOS) self-supported layer treated at $650{ }^{\circ} \mathrm{C}$ for $1 \mathrm{~h}$ is shown in Figure 4a. As can be seen, only $\mathrm{LaF}_{3} \mathrm{NCs}$, with a crystal size of $6 \mathrm{~nm}$, are obtained. On the other hand, XRD patterns of $80 \mathrm{SiO}_{2}-20 \mathrm{LaF}_{3}-0.5 \mathrm{Er}^{3+}$ (TEOS-MTES) self-supported layer treated at $550{ }^{\circ} \mathrm{C}$ for 1 min exhibited well-defined peaks consistent with the crystallization of $\mathrm{LaF}_{3}$ (JCPDS 00-032-0483) with a crystallite size of $9.0 \pm 0.5 \mathrm{~nm}$, demonstrating that only $1 \mathrm{~min}$ is sufficient to crystallize the phase, Figure $4 \mathrm{~b}$. The difference of the crystal size with respect to the TEOS sample treated at $650{ }^{\circ} \mathrm{C}$ is associated with the higher heating rate $\left(10^{\circ} \mathrm{C} / \mathrm{min}\right)$ used to crystallize the samples prepared with TEOS-MTES. The crystallization mechanism of similar GCs was extensively studied in previous papers $[44,50]$, demonstrating how the decomposition reaction of lanthanide fluoroacetates leads to precipitation of NCs once the crystallization temperature is reached. The crystallization mechanism of these materials is, therefore, completely different from that of oxyfluoride glasses by MQ in which the crystal growth is a diffusion-controlled process. Chemical bonds between fluorine and the glass matrix were observed using ${ }^{19} \mathrm{~F}$ Nuclear Magnetic Resonance (NMR) [44]. Instead, for the xerogel samples, the fluorine environment is exactly the same as in the precursor TFA acid; almost all fluorine is then found in the form of $\mathrm{LaF}_{3}$ after the crystallization process [44]. Furthermore, it was demonstrated that an increase of treatment time does not increase the crystal size or the crystal fraction of bulk samples; in contrast, crystal dissolution is observed for very long heat treatment times. Such results are clearly inconsistent with a diffusion-controlled process.
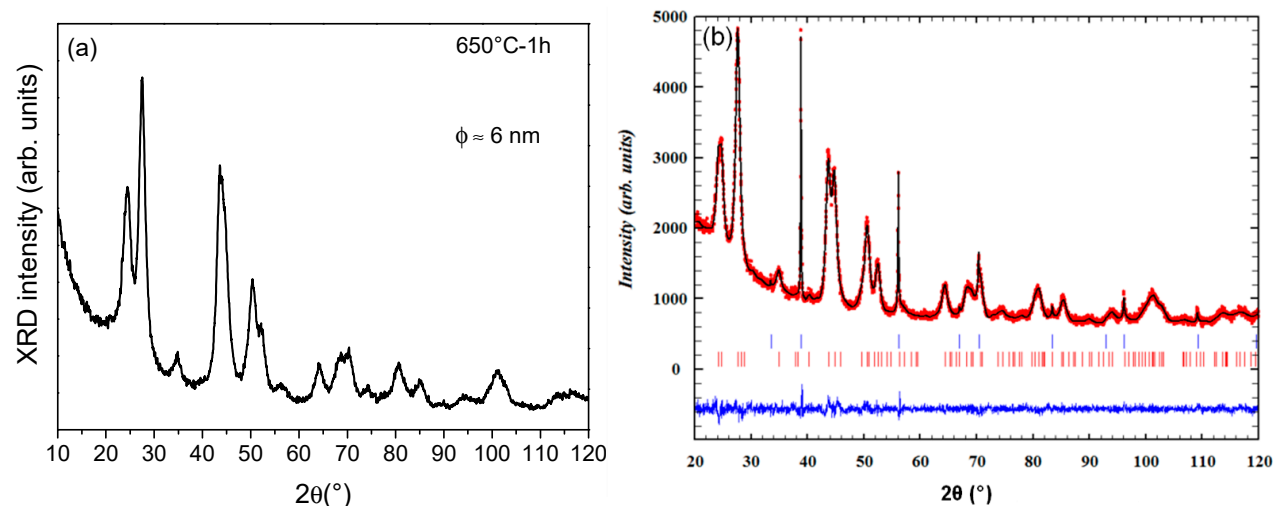

Figure 4. (a) X-Ray diffraction (XRD) of $80 \mathrm{SiO}_{2}-20 \mathrm{LaF}_{3}-01 \mathrm{Er}^{3+}$ (TEOS) self-supported layer treated at $650{ }^{\circ} \mathrm{C}$ for $1 \mathrm{~h}$. (b) Observed (small red circles), calculated (continuous black line) and difference (continuous blue line at the bottom) XRD profiles of $80 \mathrm{SiO}_{2}-20 \mathrm{LaF}_{3}-0.5 \mathrm{Er}^{3+}$ (TEOS-MTES) self-supported layer treated at $550{ }^{\circ} \mathrm{C}$ mixed with $9 \mathrm{wt}$ \% $\mathrm{NaF}$ as the internal standard. Bragg peaks of $\mathrm{NaF}$ and $\mathrm{LaF}_{3}$ are indicated by blue and red vertical bars, respectively. 
Quantitative Rietveld refinement of the $\mathrm{LaF}_{3}$ crystalline fraction with $\mathrm{NaF}$ as the internal standard was carried out for $80 \mathrm{SiO}_{2}-20 \mathrm{LaF}_{3} 0.5 \mathrm{Er}^{3+}$ bulk GC treated at $550{ }^{\circ} \mathrm{C}$ for $1 \mathrm{~min}$ following the same procedure described in [49]. The observed diffraction pattern and the difference between observed and calculated diffraction patterns are shown in Figure $4 \mathrm{~b}$. Weight fractions (wt $\%$ ) of $17.8 \%$ and $82.2 \%$ were determined for the $\mathrm{LaF}_{3}$ crystalline fraction and glassy phase, respectively. To our knowledge, this represents the highest crystal fraction reported in the literature for transparent OxGCs prepared by SG methods and it is the highest crystal fraction reported so far for $\mathrm{LaF}_{3}-\mathrm{OxGC}$ s prepared by both MQ and SG [38]. A small shift of the diffraction peaks towards higher $2 \theta$ was also observed for the $\mathrm{Er}^{3+}$-doped GC. This provides evidence of $\mathrm{Er}^{3+}$ incorporation, since the smaller $\mathrm{Er}^{3+}$ ions (1.17 $\AA$ ) on the sites of the larger $\mathrm{La}^{3+}(1.31 \AA$ ) $)$ ion decrease the unit-cell volume (Table 1$)$.

Table 1. Lattice constants of $80 \mathrm{SiO}_{2}-20 \mathrm{LaF}_{3}-0.5 \mathrm{Er}^{3+}$ (TEOS-MTES) glass-ceramic bulk sample treated at $550{ }^{\circ} \mathrm{C}$ for $1 \mathrm{~min}$.

\begin{tabular}{cccc}
\hline Sample & $\mathbf{a}(\AA)$ & $\mathbf{c}(\AA)$ & Unit Cell Volume $\left(\AA^{3}\right)$ \\
\hline Undoped $\mathrm{LaF}_{3}[\mathrm{JCPDS}]^{1}$ & 7.187 & 7.350 & 328 \\
$\mathrm{Er}^{3+}$ doped GCs $550^{\circ} \mathrm{C} 1 \mathrm{~m}$ & $7.16 \pm 0.01$ & $7.32 \pm 0.01$ & $325 \pm 1$ \\
\hline DS cards 00-032-0483. Ionic sizes in n-fold coordination for hexagonal phase: $1.31 \AA$ for $\mathrm{La}^{3+}$ and $1.17 \AA$ \\
\hline [51].
\end{tabular}

GI-XRD pattern of a thin film was obtained at the BM25B-SpLine beamline of the ESRF [39] and is shown in Figure 5a. The XRD of the bulk sample has also been acquired for comparison, Figure $5 \mathrm{~b}$. For the thin film, only a broad band, which could be deconvoluted into two peaks associated with $\mathrm{LaF}_{3}$ crystals (Figure $5 \mathrm{a}$ ). In this case, the crystallite size was much smaller, $\sim 2.5 \pm 0.5 \mathrm{~nm}$. The difference in crystallite size between bulk and film samples, is likely to be related to the synthesis and sintering conditions, since more diluted sols are necessary for film deposition with respect to bulk materials and during the sintering the coating densifies only by shrinkage normal to the substrate. Moreover, the fast evaporation of the solvent during the heat treatment may lead to the precipitation of such small NCs. This difference in crystal size between films and bulk-like materials has also been reported previously for similar systems, but a clear explanation is still necessary [52]. For comparison, Figure $5 b$ shows the XRD of the bulk samples of the same composition treated under the same conditions.
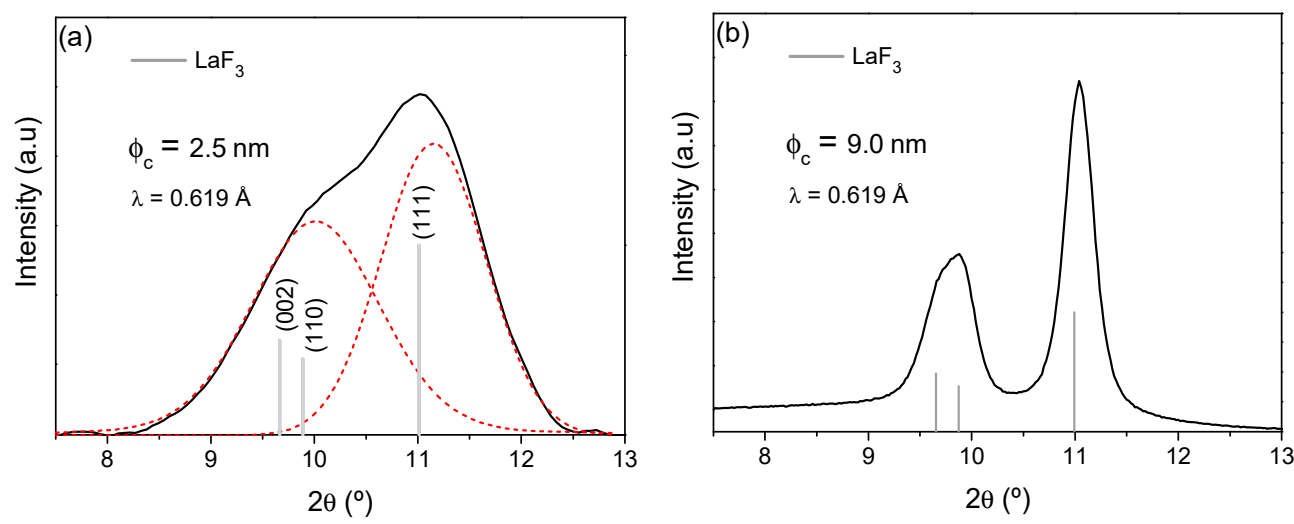

Figure 5. (a) Grazing incidence XRD (GI-XRD) of thin film and (b) XRD of the bulk sample of composition $80 \mathrm{SiO}_{2}-20 \mathrm{LaF}_{3} 0.5 \mathrm{Er}^{3+}$ (TEOS-MTES) treated at $550{ }^{\circ} \mathrm{C}$ for $1 \mathrm{~min}$. The crystal size is given together with the $\mathrm{LaF}_{3}$ reference shown with vertical bars (JCPDS 00-032-0483).

\subsection{High Resolution Transmission Electron Microscopy (HRTEM) and Nanostructure Characterization}

HRTEM was used to reveal the lattice planes and crystal-size distribution of $\mathrm{LaF}_{3}$ crystals in the thin films (Figure 6a-c) and self-supported layers (Figure $6 \mathrm{~d}-\mathrm{f}$ ) treated at $550{ }^{\circ} \mathrm{C}$ for $1 \mathrm{~min}$. Small crystals are homogeneously distributed in the glass matrix. The crystal size is around $2.0 \pm$ 
$0.5 \mathrm{~nm}$ and $8.0 \pm 0.5 \mathrm{~nm}$ for films and self-supported layers, respectively, in agreement with the GI-XRD and XRD results. A similar structure is observed in both samples, consisting of separated crystals surrounded by the residual $\mathrm{SiO}_{2}$ matrix. Fourier Transformation of the (111) crystal planes of the $\mathrm{LaF}_{3}$ Tysonite phase was employed to estimate an interplanar distance of $0.33 \mathrm{~nm}$ [53]. These results demonstrate the absence of clusters even for such short heat treatment times and further support the hypothesis that the crystallization mechanism involves chemical decomposition followed by crystal precipitation.
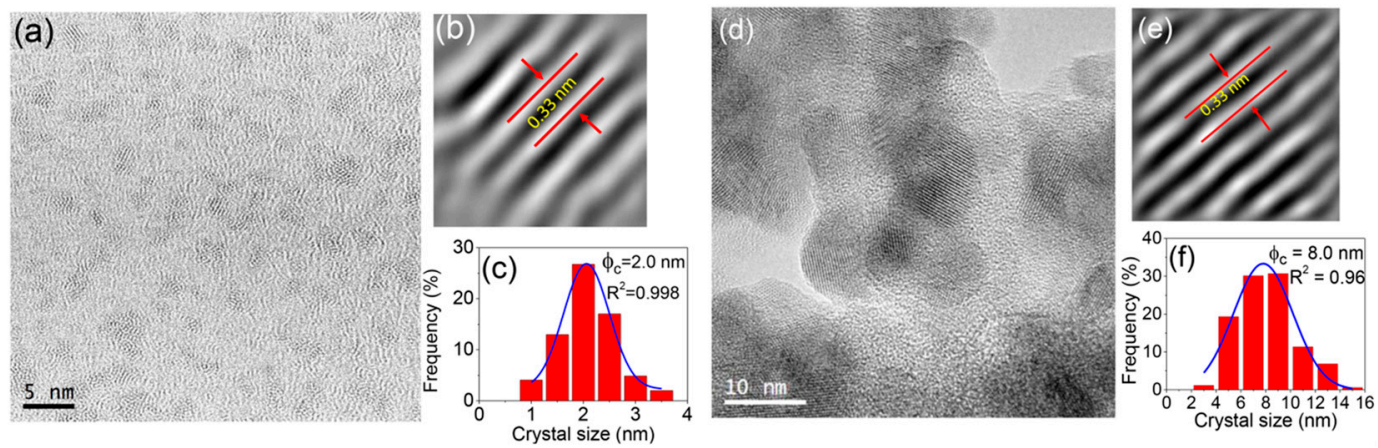

Figure 6. (a) High resolution transmission electron microscopy (HRTEM) micrograph, (b) lattice distance and (c) crystal-size distribution of $80 \mathrm{SiO}_{2}-20 \mathrm{LaF}_{3} 0.5 \mathrm{Er}^{3+}$ thin film treated at $550{ }^{\circ} \mathrm{C}$ for $1 \mathrm{~min}$. (d) HRTEM micrograph, (e) lattice distance and (f) crystal-size distribution of $80 \mathrm{SiO}_{2}-20 \mathrm{LaF}_{3} 0.5 \mathrm{Er}^{3+}$ self-supported layer treated at $550{ }^{\circ} \mathrm{C}$ for $1 \mathrm{~min}$.

\subsection{XAS, EPR and RE Environment}

A crucial aspect of RE-doped OxGCs concerns the distribution of dopants and the mechanism of incorporation into the fluoride NCs. In fact, RE ions are much more efficient when are embedded in low-phonon-energy fluoride crystals. Evidence of RE incorporation is often obtained by optical spectroscopy but sometimes only indirectly, unless specific selective excitation measurements are carried out. Here, the RE-ion environment and its role in transforming the xerogel to the GCs have been studied in detail using the local structural techniques XAS and EPR.

XAS measurements of $\mathrm{Er}_{2} \mathrm{O}_{3}$ and $\mathrm{ErF}_{3}$ were used as a reference and compared to the results of thin films doped with $0.5 \mathrm{Er}^{3+}$, Figure 7 . The presence of $\mathrm{Er}^{3+}$ is clearly indicated by the absorption edge centered around $8370 \mathrm{eV}$. However, small shifts of the edge are produced by different ligand fields. In general, for the same RE ion, the edge energy increases passing from oxides to fluorides, due to lesser hybridization of the chemical bonds in fluoride compounds attributable to a higher field strength [54-56]. In this case, the edge was obtained by the first derivative of the absorption spectrum and the edge shifts from 8356.6 to $8359 \mathrm{eV}$ passing from $\mathrm{Er}_{2} \mathrm{O}_{3}$ to $\mathrm{ErF}_{3}$. More insights are obtained by a comparison of the post-edge region that contains information about the local structure. In particular, the X-Ray Absorption Near Edge Structure (XANES), shown in Figure 7 as red and black spectra, for $\mathrm{ErF}_{3}$ and $\mathrm{Er}_{2} \mathrm{O}_{3}$, respectively, show slight differences at the white line and at resonances of $\sim 8375$ and $8395 \mathrm{eV}$. The XANES spectra and derivative of the xerogel and OxGC thin film (bottom inset of Figure 7) exhibit an absorption edge centered at $\sim 8359 \mathrm{eV}$, similar to pure $\mathrm{ErF}_{3}$. Hence, a fluorine-rich environment is already observed in the xerogel. Nevertheless, differences in the XANES region (8370-8415 eV) are observed compared to $\mathrm{ErF}_{3}$, which may indicate a change in the $\mathrm{Er}^{3+}$ environment for the xerogel and the OxGC samples. Fourier-Transform calculations indicate a narrowing of the first shell as the xerogel transforms to the OxGC, which is consistent with the development of a higher symmetry environment corresponding to the fluoride crystalline phase. 


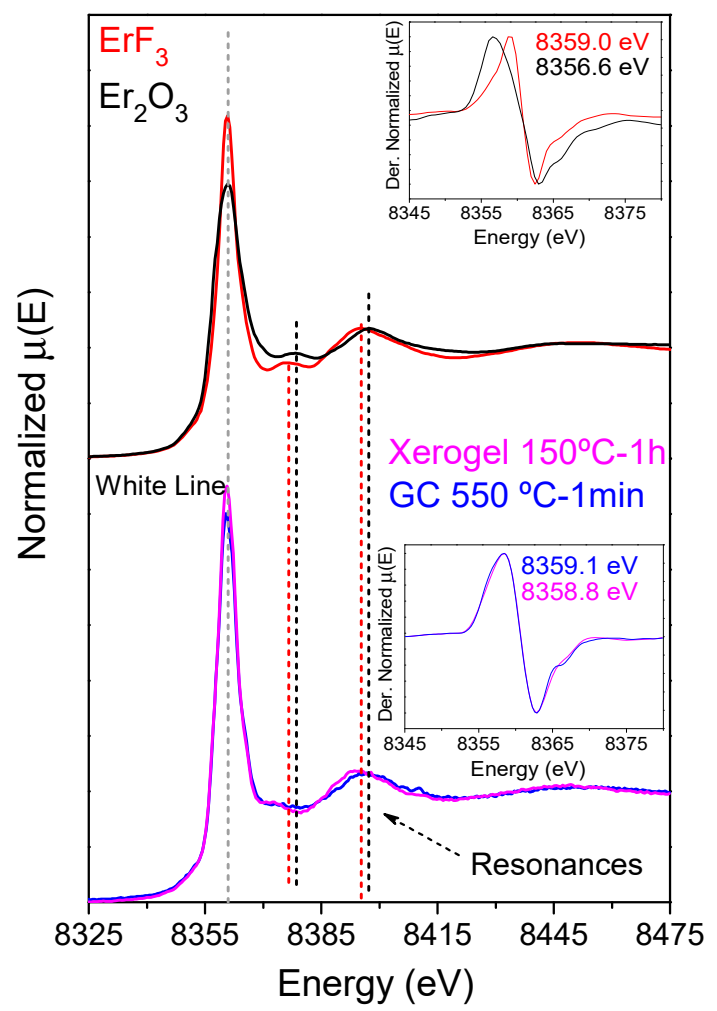

Figure 7. X-Ray absorption spectroscopy (XAS) spectra and derivatives (inset) of $\mathrm{Er}_{2} \mathrm{O}_{3}$ and $\operatorname{ErF}_{3}$ references in black and red, respectively (top), and of XAS spectra and derivatives (inset) of $80 \mathrm{SiO}_{2}-20 \mathrm{LaF}_{3}-0.5 \mathrm{Er}^{3+}$ (TEOS-MTES) xerogel and GC thin film treated at $550{ }^{\circ} \mathrm{C}$ for $1 \mathrm{~min}$, in pink and blue, respectively (bottom). The grey line indicates the white line and the red and black lines indicate resonance positions for $\mathrm{ErF}_{3}$ and $\mathrm{Er}_{2} \mathrm{O}_{3}$, respectively.

A linear combination of XANES spectra in the range $8325-8475 \mathrm{eV}$ was performed for the OxGC sample using the standard $\mathrm{ErF}_{3}$ and $\mathrm{Er}_{2} \mathrm{O}_{3}$ materials. Employing the crystal fraction of $\mathrm{LaF}_{3}$ calculated by Rietveld refinement, approximate fractions of $91 \%$ and $9 \%$ were calculated for $\mathrm{Er}^{3+}$ in $\mathrm{ErF}_{3}$ and $\mathrm{Er}_{2} \mathrm{O}_{3}$-like environments, respectively. Thus, the $\mathrm{Er}^{3+}$ ions are likely to be situated near fluoride ions in the xerogel state, precipitating in fluoride-rich crystals after the heat treatment at $550{ }^{\circ} \mathrm{C}$ for $1 \mathrm{~min}$. These results are explained considering that, in the starting sol, the $\mathrm{La}^{3+}$ and $\mathrm{Er}^{3+}$ ions are surrounded by TFA cations that are screened and impeded from bonding with $\mathrm{Si}$ atoms. Hence, in the xerogel sample, fluorine is still coordinated as in TFA acid [44] and $\mathrm{Er}^{3+}$ ions are principally coordinated by fluorine. During the heat treatment, decomposition promotes the precipitation of $\mathrm{LaF}_{3}$ crystals in which $\mathrm{Er}^{3+}$ ions become trapped. Other techniques, such as Energy Dispersive X-Ray Spectroscopy (EDXS), demonstrated an Eu enrichment in $\mathrm{GdF}_{3} \mathrm{NCs}$ after just 1 min of treatment at $550{ }^{\circ} \mathrm{C}$ [50], further supporting the aforementioned conclusions.

Once the crystal fraction is obtained, an indication of the concentration of $\mathrm{RE}$ ions in $\mathrm{LaF}_{3}$ crystals may be obtained. Supposing that $91 \%$ of $\mathrm{Er}^{3+}$ ions are embedded in the crystal phase and that the crystalline fraction is $\sim 18 \mathrm{wt} \%$ (XRD), the effective concentration of $\mathrm{Er}^{3+}$ ions in the crystal phase is around $6.5 \mathrm{~mol} \%$, representing an order of magnitude increase with respect to the nominal concentration $(0.5 \mathrm{~mol} \%)$. Similar values were obtained in previous studies of samples prepared by $M Q$, albeit with a lower fraction of RE ions incorporated in the crystal phase [57].

Further evidence supporting the mechanism for the incorporation RE ions is obtained by EPR of the self-supported layers. Figure 8 shows the EPR spectra of xerogel samples doped with $0.5 \mathrm{Er}^{3+}$ $(\mathrm{mol} \%)$ measured at $5 \mathrm{~K}$. The EPR signal of a glass, prepared by MQ, containing $0.5 \mathrm{Er}^{3+}$ in an amorphous fluorine-rich environment is also shown for comparison. Several resonances are observed for the xerogel samples, due to the presence of organic compounds which remain after heat treatment 
at $50{ }^{\circ} \mathrm{C} . \mathrm{Er}^{3+}$ resonances are associated with the broad signals appearing in the range 500-1000 G. Other authors reported EPR measurements of $\mathrm{Er}^{3+}$ in oxyfluoride glasses showing the presence of broad signals at low magnetic fields (high $g$ values) [58]. Moreover, such resonances disappear at room temperature (RT) and are only visible below $20 \mathrm{~K}$, indicating that they are associated with $\mathrm{Er}^{3+}$ ions. Such broad signals are clearly related to an amorphous environment typical of glasses and liquids. The EPR signal of an oxyfluoride glass doped with $0.5 \mathrm{Er}^{3+}$ prepared by MQ is also shown for comparison. The signal around $2300 \mathrm{G}$, observed only in the xerogel, is attributed to the presence of organic compounds. Interesting results are obtained for the GC samples, which display resonances associated with paramagnetic species with effective spin $S^{\prime}=1 / 2$ in rhombic or lower symmetry after just $1 \mathrm{~min}$ of heat treatment; the resonances appear at $g$ values of $g_{1}=11.2 ; g_{2}=4.9$ and $g_{3}=3.1$. On comparison with the EPR results obtained for an $\mathrm{Er}^{3+}$-doped $\mathrm{LaF}_{3}$ single crystal $[59,60]$, it can be unambiguously concluded that the resonances in the GC samples are those of $\mathrm{Er}^{3+}$ in $\mathrm{LaF}_{3} \mathrm{NCs}_{\text {. }}$ Broader signals are observed for the GC doped with $0.5 \mathrm{Er}^{3+}$ and associated with stronger relaxation processes, due to a moderately high effective concentration.
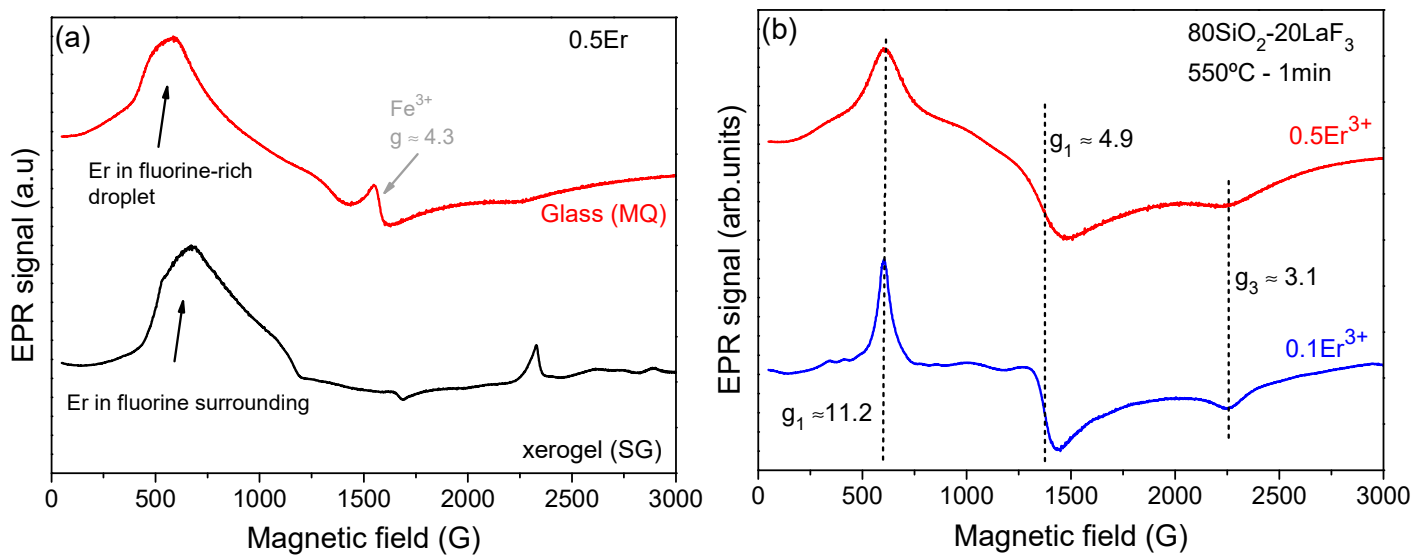

Figure 8. (a) Electron Paramagnetic Resonance (EPR) signals for the $80 \mathrm{SiO}_{2}-20 \mathrm{LaF}_{3}-0.5 \mathrm{Er}^{3+}$ (TEOS-MTES). xerogel and of an MQ glass doped with $0.5 \mathrm{Er}^{3+}$. (b) EPR signals of $80 \mathrm{SiO}_{2}-20 \mathrm{LaF}_{3}$ (TEOS-MTES) GCs doped with 0.1 and $0.5 \mathrm{Er}^{3+}(\mathrm{mol} \%)$ treated at $550{ }^{\circ} \mathrm{C}$ for $1 \mathrm{~min}$.

For the composition with a lower concentration of dopant, the hyperfine structure is only partially resolved, due to the interaction of the electrons with nuclear spins. The low intensity of the hyperfine structure is due to the quantity of Er isotope nuclei with $I=7 / 2(\sim 23 \%)$, while the remaining nuclei $(77 \%)$ with $I=0$ do not produce any hyperfine interaction $[58,61,62]$. For the composition doped with $0.5 \mathrm{Er}^{3+}$, the hyperfine structure is too broad to be resolved but its presence may be discerned from the shape of the resonance at $g_{1}=11.2$ which presents broader sidebands. Another interesting result is the absence of any further $\mathrm{Er}^{3+}$ resonance other than that of $\mathrm{Er}^{3+}$ in the $\mathrm{LaF}_{3} \mathrm{NCs}$.

These results, together with the previous discussion of XAS measurements, indicate that dopant incorporation occurs with crystal precipitation. In contrast, in melted glasses, residual contributions of RE ions in an amorphous environment are still observed even after the crystallization process, confirming that some RE ions remain in the glass matrix or in phase-separation droplets.

\subsection{Photoluminescence (PL)}

The near-infrared emission spectra corresponding to the ${ }^{4} \mathrm{I}_{13 / 2} \rightarrow{ }^{4} \mathrm{I}_{15 / 2}$ transition for $80 \mathrm{SiO}_{2}$ $20 \mathrm{LaF}_{3}-0.5 \mathrm{Er}^{3+}$ (TEOS-MTES) self-supported layer heat treated at $550{ }^{\circ} \mathrm{C}$ for $1 \mathrm{~min}$ were obtained at room temperature and at $9 \mathrm{~K}$ by exciting at $793 \mathrm{~nm}$ in the ${ }^{4} \mathrm{I}_{15 / 2} \rightarrow{ }^{4} \mathrm{I}_{9 / 2}$ absorption band. After excitation of this level, the next lower levels are populated by multiphonon relaxations. The room temperature emission spectrum (Figure 9a) shows a series of peaks with a maximum of around $1540 \mathrm{~nm}$. Figure $9 \mathrm{~b}$ shows the excitation spectrum corresponding to the ${ }^{4} \mathrm{I}_{15 / 2} \rightarrow{ }^{4} \mathrm{I}_{9 / 2}$ transition obtained by collecting 
the luminescence spectrum at $1540 \mathrm{~nm}$, revealing well defined peaks which suggest the partial incorporation of $\mathrm{Er}^{3+}$ ions in the $\mathrm{LaF}_{3} \mathrm{NCs}$.
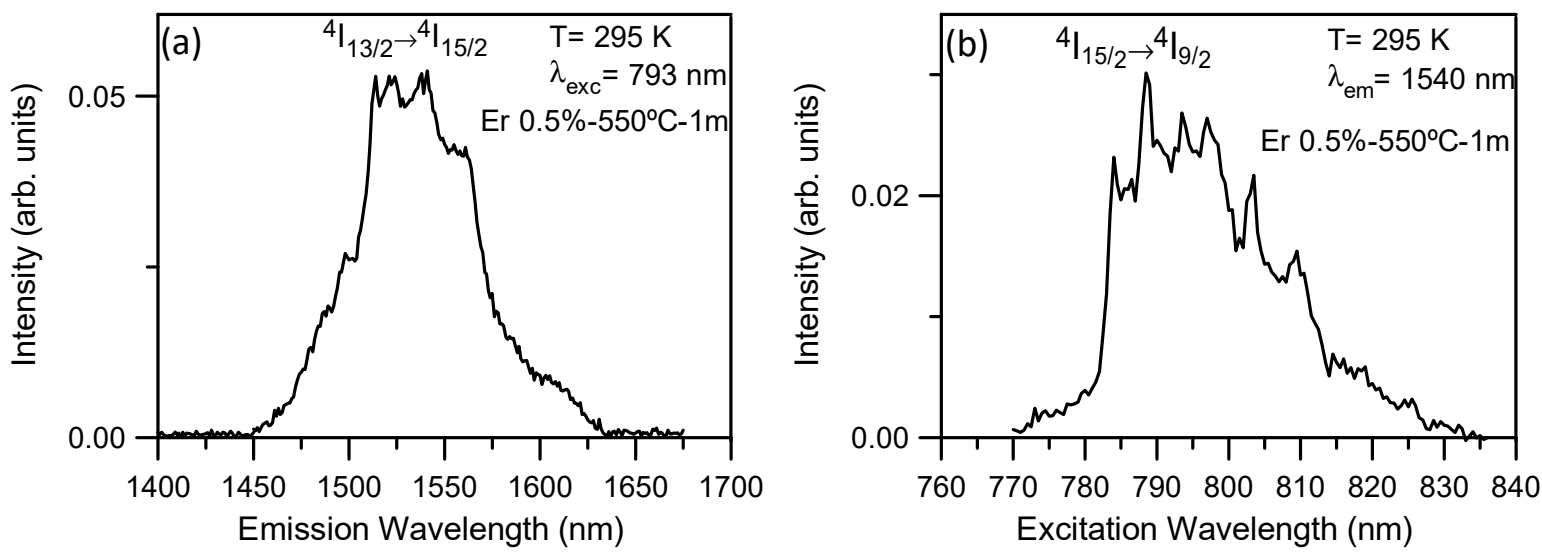

Figure 9. (a) Room temperature emission spectrum of $80 \mathrm{SiO}_{2}-20 \mathrm{LaF}_{3}-0.5 \mathrm{Er}^{3+}$ (TEOS-MTES) bulk sample heat treated at $550{ }^{\circ} \mathrm{C}$ for $1 \mathrm{~min}$ obtained on exciting at $793 \mathrm{~nm}$. (b) Low-temperature excitation spectrum obtained at $1540 \mathrm{~nm}$.

The incorporation of $\mathrm{Er}^{3+}$ ions into $\mathrm{LaF}_{3} \mathrm{NCs}$ is unambiguously confirmed by measurements performed at low temperature. Figure 10 shows the emission and excitation spectra, respectively, obtained at $9 \mathrm{~K}$. The emission spectrum shows sharp peaks superimposed on a broad band. The excitation spectrum obtained by collecting the luminescence at the emission maximum also shows very well defined peaks. The features exhibited by the low-temperature spectra confirm the partial incorporation of $\mathrm{Er}^{3+}$ ions in the NCs and provide evidence of the crystalline and amorphous $\mathrm{Er}^{3+}$ environments.
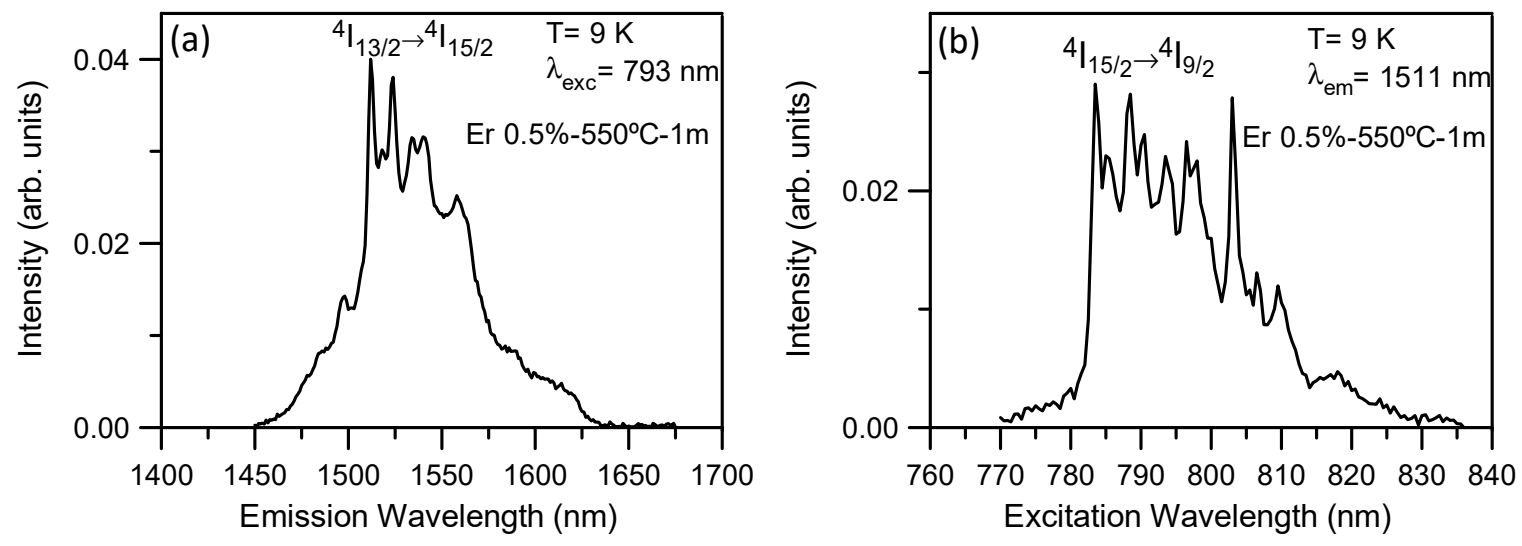

Figure 10. (a) Low temperature emission spectrum of $80 \mathrm{SiO}_{2}-20 \mathrm{LaF}_{3}-0.5 \mathrm{Er}^{3+}$ (TEOS-MTES) bulk sample heat treated at $550{ }^{\circ} \mathrm{C}$ for $1 \mathrm{~min}$ on exciting at $793 \mathrm{~nm}$. (b) Low temperature excitation spectrum obtained at $1511 \mathrm{~nm}$.

Measurements performed for the $80 \mathrm{SiO}_{2}-20 \mathrm{LaF}_{3}-0.1 \mathrm{Er}^{3+}$ (TEOS) bulk sample heat treated at $650{ }^{\circ} \mathrm{C}$ for $1 \mathrm{~h}$ suggest that $\mathrm{Er}^{3+}$ ions are mainly incorporated in $\mathrm{LaF}_{3} \mathrm{NCs}$. As an example, Figure 11a shows the low-temperature emission spectrum obtained on exciting at $793 \mathrm{~nm}$. In this case, sharp and well-defined peaks are observed. Moreover, the excitation spectrum obtained by collecting the luminescence at the emission maximum corresponds to a crystalline environment for $\mathrm{Er}^{3+}$ ions. Similar emission spectra are obtained by exciting different peaks in the spectrum. 

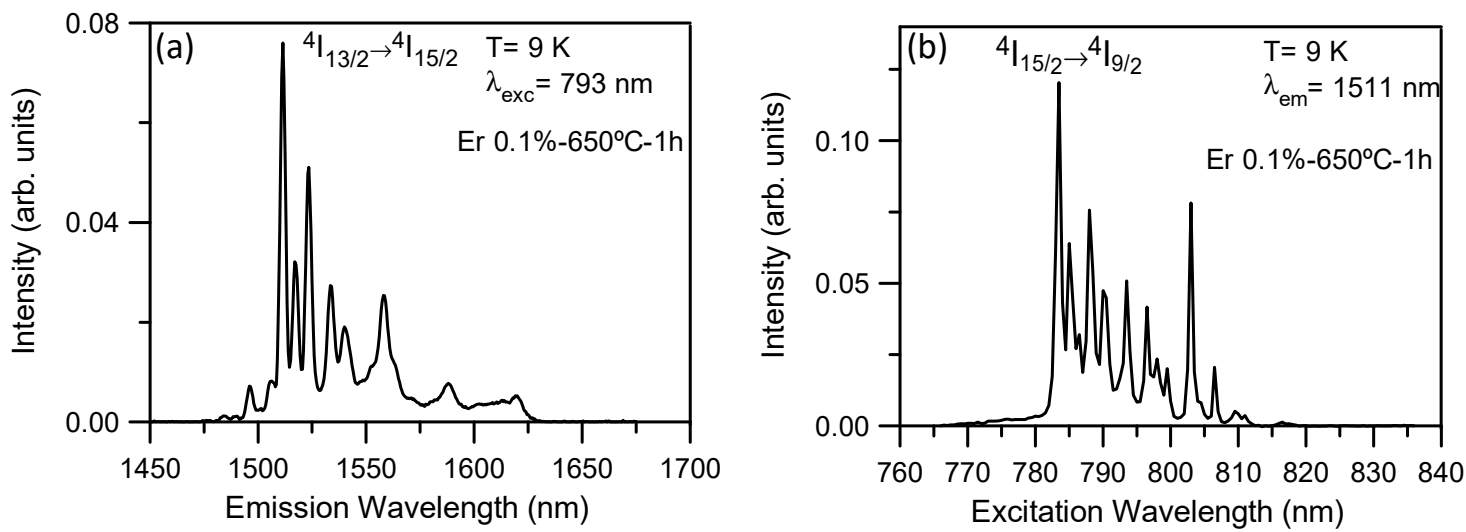

Figure 11. (a) Low-temperature emission spectrum of the $80 \mathrm{SiO}_{2}-20 \mathrm{LaF}-0.1 \mathrm{Er}^{3+}$ (TEOS) bulk sample heat treated at $650{ }^{\circ} \mathrm{C}$ for $1 \mathrm{~h}$ on exciting at $793 \mathrm{~nm}$. (b) Low temperature excitation spectrum obtained at $1511 \mathrm{~nm}$.

These results confirm that, in the $80 \mathrm{SiO}_{2}-20 \mathrm{LaF}_{3}-0.1 \mathrm{Er}^{3+}$ (TEOS) bulk sample, the $\mathrm{Er}^{3+}$ ions are mainly located in the $\mathrm{LaF}_{3} \mathrm{NCs}$. Although, the emission and excitation spectra of the $80 \mathrm{SiO}_{2}-20 \mathrm{LaF}_{3}-0.5 \mathrm{Er}^{3+}$ (TEOS/MTES) bulk sample also show well-defined peaks, they are much broader and less well resolved than those of the less concentrated sample, suggesting the presence of both crystalline and amorphous $\mathrm{Er}^{3+}$ environments in the $0.5 \% \mathrm{Er}^{3+}$-doped $80 \mathrm{SiO}_{2}-20 \mathrm{LaF}_{3}$ sample.

Another important spectroscopic parameter to characterize the luminescent behavior of $\mathrm{Er}^{3+}$ ions is the decay time of the emitting level. The lifetime of the ${ }^{4} \mathrm{I}_{13 / 2}$ level was obtained at $9 \mathrm{~K}$ by exciting at $793 \mathrm{~nm}$ and collecting the luminescence at $1511 \mathrm{~nm}$. The decay for the $80 \mathrm{SiO}_{2}-20 \mathrm{LaF}_{3}-0.1 \mathrm{Er}^{3+}(\mathrm{TEOS})$ bulk sample (Figure 12) deviates from a single exponential function and the lifetime is unexpectedly short. The average lifetime, calculated by:

$$
\langle\tau\rangle=\frac{\int_{0}^{\infty} t I(t) d t}{\int_{0}^{\infty} I(t) d t}
$$

where $I(t)$ represents the luminescence intensity at time $t$ corrected for the background, is around $0.79 \mathrm{~ms}$. This lifetime is nearly one order of magnitude shorter than those observed in bulk samples prepared by MQ [13]. Similar behavior has also been observed in $\mathrm{Nd}^{3+}$-doped $80 \mathrm{SiO}_{2}-20 \mathrm{LaF}_{3}$ thin films, and attributed to the fact that the effective $\mathrm{RE}^{3+}$-ion concentration in the NCs differs by up to an order of magnitude from the theoretical (or nominal) value [12,52].

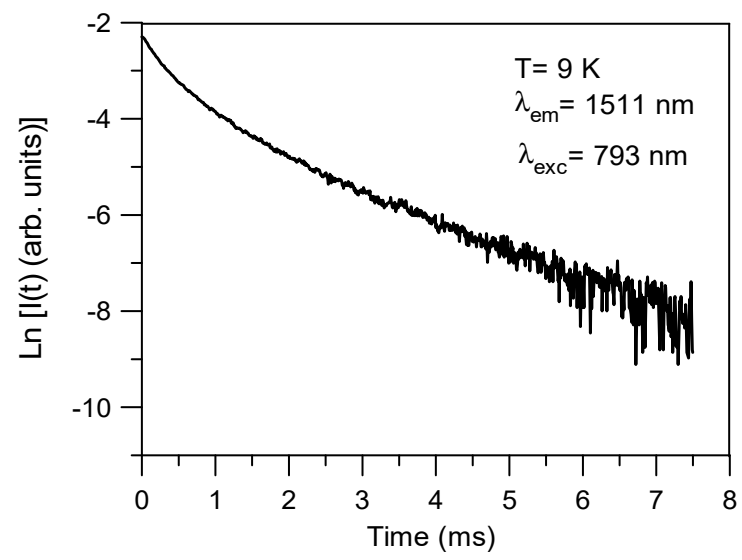

Figure 12. Semi-logarithmic plot of the fluorescence decay of the ${ }^{4} \mathrm{I}_{13 / 2}$ level for the $80 \mathrm{SiO}_{2}-20 \mathrm{LaF}_{3}$ $0.1 \mathrm{Er}^{3+}$ (TEOS) bulk sample doped with $0.1 \% \mathrm{Er}^{3+}$ obtained by exciting at $793 \mathrm{~nm}$ and collecting the luminescence at $1511 \mathrm{~nm}$. 
The room temperature emission spectra of $80 \mathrm{SiO}_{2}-20 \mathrm{LaF}_{3}$ (TEOS-MTES) thin films doped with 0.1 and $0.5 \mathrm{Er}^{3+}$ heat treated at $550{ }^{\circ} \mathrm{C}$ for $1 \mathrm{~h}$ corresponding to the ${ }^{4} \mathrm{I}_{13 / 2} \rightarrow{ }^{4} \mathrm{I}_{15 / 2}$ transition obtained by exciting at $980 \mathrm{~nm}$ reveal a glass-like behavior. Figure 13 shows the emission spectra for thin films doped with 0.1 and $0.5 \% \mathrm{Er}^{3+}$. In both samples the spectrum shows an unresolved structure with a maximum at around $1540 \mathrm{~nm}$ which indicates the absence of a crystalline environment for $\mathrm{Er}^{3+}$ ions.

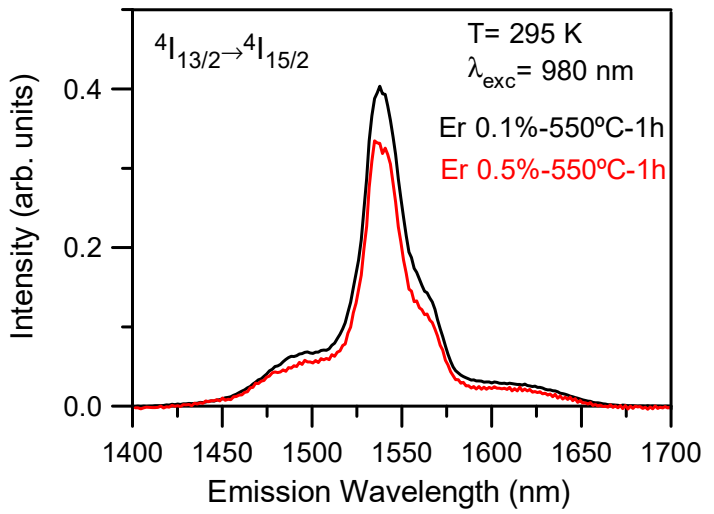

Figure 13. Room temperature emission spectrum of $80 \mathrm{SiO}_{2}-20 \mathrm{LaF}_{3}$ (TEOS-MTES) thin films doped with $0.1 \%$ (black line) and $0.5 \%$ (red line) $\mathrm{Er}^{3+}$ heat treated at $550{ }^{\circ} \mathrm{C}$ for $1 \mathrm{~h}$ obtained on exciting at $980 \mathrm{~nm}$.

\section{Conclusions}

For the first time the preparation of transparent oxyfluoride glass ceramics of composition $80 \mathrm{SiO}_{2}-20 \mathrm{LaF}_{3}$ containing $\mathrm{Er}^{3+}$-dopant have been prepared by sol-gel using TEOS and MTES as silica precursors. XRD and HRTEM showed the precipitation of $\mathrm{LaF}_{3}$ nanocrystals, with a size of 9 and $3 \mathrm{~nm}$, after heat treatment at $550{ }^{\circ} \mathrm{C}$ for $1 \mathrm{~min}$ for bulk and thin film, respectively. Rietveld refinement indicated a $\mathrm{LaF}_{3}$ crystal fraction of $\sim 18 \mathrm{wt} \%$ for the bulk glass ceramic. To our knowledge, this represents the highest crystal fraction reported in the literature for transparent oxyfluoride glass ceramics prepared by both melt-quenching and sol-gel methods. XAS and EPR shown a fluorine-rich amorphous environment in the xerogel and confirmed the presence of $\mathrm{Er}^{3+}$ in the $\mathrm{LaF}_{3}$ nanocrystals after crystallization, with a concentration around one order of magnitude higher than the nominal value. No XAS and EPR results have previously been reported for RE-doped oxyfluoride glass-ceramics prepared by sol-gel. The incorporation of $\mathrm{Er}^{3+}$ ions into $\mathrm{LaF}_{3}$ nanocrystals was unambiguously confirmed by measurements performed at low temperature. For doping levels higher than $0.1 \mathrm{~mol} \%$, contributions from crystalline and amorphous environments are observed. A clear difference is found between the emission spectra of thin films and bulk samples, likely related to the different crystal size.

Author Contributions: Conceptualization, G.G., J.J.V., J.M., R.B., J.F., A.D. and Y.C.; methodology, G.G., J.J.V., A.S, M.V., G.R.C., D.B. and R.B.; software, G.G., J.J.V., G.C.M., A.S., M.V. and R.B.; formal analysis, G.G., J.J.V., A.S., M.V., G.R.C., D.B. and R.B.; investigation, G.G., J.J.V., A.S., M.V., G.R.C., D.B. and R.B.; resources, A.D., Y.C., G.R.C., D.B., R.B. and J.F.; data curation, G.G., J.J.V., A.S., M.V., G.R.C., D.B. and R.B.; writing-original draft, G.G., J.J.V., J.M., A.S., M.V. and R.B.; writing-review and editing, G.G., J.J.V., G.C.M., G.R.C., D.B., R.B., J.F., A.D. and Y.C.; visualization, G.G., J.J.V., A.S., M.V., D.B., R.B. and J.F.; supervision, R.B., J.F., A.D. and Y.C.; project administration, R.B., J.F., J.M., A.D. and Y.C.; funding acquisition, R.B., J.F., A.D. and Y.C.

Funding: This research was funded by Spanish National projects MAT2017-87035-C2-1-P/2-P (AEI/FEDER, UE), MAT2016-75362-C3-1-R, and Basque Country University PPG17/07 and GIU17/014.

Acknowledgments: We acknowledge The European Synchrotron Radiation Facility (ESRF), MINECO, and CSIC for the provision of measurements using the BM25-SpLine beamline. This paper is a part of dissemination activities of project FunGlass. This project has received funding from the European Union's Horizon 2020 research and innovation programme under grant agreement No 739566. A.S. acknowledges the financial support from the Comunidad de Madrid for an "Atracción de Talento Investigador" contract (No. 2017-t2/IND5395).

Conflicts of Interest: The authors declare no conflict of interest. 


\section{References}

1. Wang, Y.; Ohwaki, J. New transparent vitroceramics codoped with $\mathrm{Er}^{3+}$ and $\mathrm{Yb}^{3+}$ for efficient frequency upconversion. Appl. Phys. Lett. 1993, 63, 3268-3270. [CrossRef]

2. Dejneka, M.J. The luminescence and structure of novel transparent oxyfluoride glass-ceramics. J. Non-Cryst. Solids 1998, 239, 149-155. [CrossRef]

3. Tanabe, S.; Hayashi, H.; Hanada, T.; Onodera, N. Fluorescence properties of $\mathrm{Er}^{3+}$ ions in glass ceramics containing $\mathrm{LaF}_{3}$ nanocrystals. Opt. Mater. 2002, 19, 343-349. [CrossRef]

4. Lavin, V.; Iparraguirre, I.; Azkargorta, J.; Mendioroz, A.; González-Plata, J.; Balda, R.; Fernández, J. Stimulated and upconverted emissions of $\mathrm{Nd}^{3+}$ in a transparent oxyfluoride glass-ceramic. Opt. Mater. (Amst.) 2004, 25, 201-208. [CrossRef]

5. Mattarelli, M.; Tikhomirov, V.K.; Seddon, A.B.; Montagna, M.; Moser, E. Tm ${ }^{3+}$-activated transparent oxy-fluoride glass-ceramics: Structural and spectroscopic properties. J. Non-Cryst. Solids 2004, 346, 354-358. [CrossRef]

6. Chen, D.; Wang, Y.; Yu, Y.; Huang, P.; Weng, F. Near-infrared quantum cutting in $\mathrm{Ho}^{3+} / \mathrm{Yb}^{3+}$ codoped nanostructured glass ceramic. Opt. Lett. 2011, 36, 876-878.

7. de Pablos-Martín, A.; Durán, A.; Pascual, M.J. Nanocrystallization in oxyfluoride systems: Mechanisms of crystallization and photonic properties. Int. Mater. Rev. 2012, 57, 165-186. [CrossRef]

8. Wei, Y.; Li, J.; Yang, J.; Chi, X.; Guo, H. Enhanced green upconversion in $\mathrm{Tb}^{3+}-\mathrm{Yb}^{3+}$ co-doped oxyfluoride glass ceramics containing $\mathrm{LaF}_{3}$ nanocrystals. J. Lumin. 2013, 137, 70-72. [CrossRef]

9. de Pablos-Martín, A.; Ferrari, M.; Pascual, M.J.; Righini, G.C. Glass-ceramics: A class of nanostructured materials for photonics. Riv. Nuovo Cimento 2015, 38, 311-369.

10. Fedorov, P.P.; Luginina, A.A.; Popov, A.I. Transparent oxyfluoride glass ceramics. J. Fluor. Chem. 2015, 172, 22-50. [CrossRef]

11. Pascual, M.J.; Garrido, C.; Durán, A.; Pascual, L.; de Pablos-Martín, A.; Fernández, J.; Balda, R. Optical Properties of Transparent Glass-Ceramics Containing $\mathrm{Er}^{3+}$-Doped Sodium Lutetium Fluoride Nanocrystals. Int. J. Appl. Glass Sci. 2016, 40, 27-40. [CrossRef]

12. Gorni, G.; Velázquez, J.J.; Mather, G.C.; Durán, A.; Chen, G.; Sundararajan, M.; Balda, R.; Fernández, J.; Pascual, M.J. Selective excitation in transparent oxyfluoride glass-ceramics doped with $\mathrm{Nd}^{3+}$. J. Eur. Ceram. Soc. 2017, 37, 1695-1706. [CrossRef]

13. Gorni, G.; Balda, R.; Fernández, J.; Pascual, L.; Durán, A.; Pascual, M.J. Effect of the heat treatment on the spectroscopic properties of $\mathrm{Er}^{3+}-\mathrm{Yb}^{3+}$ - doped transparent oxyfluoride nano-glass-ceramics. J. Lumin. 2018, 193, 51-60. [CrossRef]

14. Velázquez, J.J.; Balda, R.; Fernández, J.; Gorni, G.; Pascual, L.; Chen, G.; Sundararajan, M.; Durán, A.; Pascual, M.J. Transparent oxy fl uoride glass-ceramics with $\mathrm{NaGdF}_{4}$ nanocrystals doped with $\operatorname{Pr}^{3+}$ and $\mathrm{Pr}^{3+}-\mathrm{Yb}^{3+}$. J. Lumin. 2018, 193, 61-69. [CrossRef]

15. Samson, B.N.; Tick, P.A.; Borrelli, N.F. Efficient neodymium-doped glass-ceramic fiber laser and amplifier. Opt. Lett. 2001, 26, 145-147. [CrossRef]

16. Reben, M.; Jaglarz, J. $\mathrm{Nd}^{3+}$-Doped Oxyfluoride Glass Ceramics Optical Fibre with $\mathrm{SrF}_{2}$ Nanocrystals. Opt. Appl. 2012, 42, 353-364.

17. Lisiecki, R.; Augustyn, E.; Ryba-romanowski, W.; Zelechower, M. Er-doped and Er, Yb co-doped oxyfluoride glasses and glass-ceramics, structural and optical properties. Opt. Mater. 2011, 33, 1630-1637. [CrossRef]

18. Kang, S.; Fang, Z.; Huang, X.; Chen, Z.; Yang, D.; Xiao, X.; Qiu, J.; Dong, G. Precisely controllable fabrication of $\mathrm{Er}^{3+}$-doped glass ceramic fibers: Novel mid-infrared fiber laser materials. J. Mater. Chem. C 2017, 5, 4549-4556. [CrossRef]

19. Gorni, G.; Balda, R.; Fernández, J.; Iparraguirre, I.; Velázquez, J.J.; Castro, Y.; Pascual, L.; Chen, G.; Sundararajan, M.; Pascual, M.J.; et al. Oxyfluoride glass-ceramic fibers doped with $\mathrm{Nd}^{3+}$ : Structural and optical characterization. CrystEngComm 2017, 19, 6620-6629. [CrossRef]

20. Kang, S.; Yu, H.; Ouyang, T.; Chen, Q.; Huang, X.; Chen, Z.; Qiu, J.; Dong, G. Novel Er ${ }^{3+} / \mathrm{Ho}^{3+}$-codoped glass-ceramic fibers for broadband tunable mid-infrared fiber lasers. J. Am. Ceram. Soc. 2018, 101, 3956-3967. [CrossRef]

21. Fujihara, S.; Mochizuki, C.; Kimura, T. Formation of $\mathrm{LaF}_{3}$ microcrystals in sol-gel silica. J. Non-Cryst. Solids 1999, 244, 267-274. [CrossRef] 
22. Biswas, A.; Maciel, G.S.; Friend, C.S.; Prasad, P.N. Upconversion properties of a transparent $\mathrm{Er}^{3+}-\mathrm{Yb}^{3+}$ co-doped $\mathrm{LaF}_{3}-\mathrm{SiO}_{2}$ glass-ceramics prepared by sol-gel method. J. Non-Cryst. Solids 2003, 316, 393-397. [CrossRef]

23. Fujihara, S.; Koji, S.; Kimura, T. Structure and optical properties of (Gd,Eu) $\mathrm{F}_{3}$-nanocrystallized sol-gel silica films. J. Mater. Chem. 2004, 14, 1331-1335. [CrossRef]

24. Ribeiro, S.J.L.; Araújo, C.C.; Bueno, L.A.; Gonçalves, R.R.; Messaddeq, Y. Sol-gel $\mathrm{Eu}^{3+} / \mathrm{Tm}^{3+} \mathrm{doped}^{2}$ transparent glass-ceramic waveguides. J. Non-Cryst. Solids 2004, 348, 180-184. [CrossRef]

25. Luo, W.; Wang, Y.; Bao, F.; Zhou, L.; Wang, X. Crystallization behavior of PbF2-SiO2based bulk xerogels. J. Non-Cryst. Solids 2004, 347, 31-38. [CrossRef]

26. Zhou, L.; Chen, D.; Luo, W.; Wang, Y.; Yu, Y.; Liu, F. Transparent glass ceramic containing $\mathrm{Er}^{3+}: \mathrm{CaF}_{2}$ nano-crystals prepared by sol-gel method. Mater. Lett. 2007, 61, 3988-3990. [CrossRef]

27. Velázquez, J.J.; Yanes, A.C.; Del-Castillo, J.; Méndez-Ramos, J.; Rodríguez, V.D. Optical properties of $\mathrm{Ho}^{3+}-\mathrm{Yb}^{3+}$ co-doped nanostructured $\mathrm{SiO}_{2}-\mathrm{LaF}_{3}$ glass-ceramics prepared by sol-gel method. Phys. Status Solidi 2007, 204, 1762-1768. [CrossRef]

28. del-Castillo, J.; Yanes, A.C. Bright luminescence of $\mathrm{Gd}^{3+}$ sensitized $\mathrm{RE}^{3+}$-doped $\mathrm{SiO}_{2}-\mathrm{BaGdF}_{5}$ glass-ceramics for UV-LEDs colour conversion. J. Alloys Compd. 2017, 695, 3736-3743.

29. Szpikowska-Sroka, B.; Pawlik, N.; Goryczka, T.; Pietrasik, E.; Bańczyk, M.; Pisarski, W.A. Lead fluoride $\beta-\mathrm{PbF}_{2}$ nanocrystals containing $\mathrm{Eu}^{3+}$ and $\mathrm{Tb}^{3+}$ ions embedded in sol-gel materials: Thermal, structural and optical investigations. Ceram. Int. 2017, 43, 8424-8432. [CrossRef]

30. Szpikowska-Sroka, B.; Pawlik, N.; Goryczka, T.; Pisarski, W.A. Influence of silicate sol-gel host matrices and catalyst agents on the luminescent properties of $\mathrm{Eu}^{3+} / \mathrm{Gd}^{3+}$ under different excitation wavelengths. RSC Adv. 2015, 5, 98773-98782. [CrossRef]

31. Secu, C.E.; Bartha, C.; Polosan, S.; Secu, M. Thermally activated conversion of a silicate gel to an oxyfluoride glass ceramic: Optical study using $\mathrm{Eu}^{3+}$ probe ion. J. Lumin. 2014, 146, 539-543. [CrossRef]

32. Secu, C.E.; Negrea, R.F.; Secu, M. Eu ${ }^{3+}$ probe ion for rare-earth dopant site structure in sol-gel derived LiYF4 oxyfluoride glass-ceramic. Opt. Mater. 2013, 35, 2456-2460. [CrossRef]

33. Santana-Alonso, A.; Méndez-Ramos, J.; Yanes, A.C.; Del-Castillo, J.; Rodríguez, V.D. Up-conversion in sol-gel derived nano-glass-ceramics comprising $\mathrm{NaYF}_{4}$ nano-crystals doped with $\mathrm{Yb}^{3+}, \mathrm{Ho}^{3+}$ and $\mathrm{Tm}^{3+}$. Opt. Mater. 2010, 32, 903-908. [CrossRef]

34. Szpikowska-Sroka, B.; Zur, L.; Czoik, R.; Goryczka, T.; Swinarew, A.S.; Zadlo, M.; Pisarski, W.A. Long-lived emission from $\mathrm{Eu}^{3+}: \mathrm{PbF}_{2}$ nanocrystals distributed into sol-gel silica glass. J. Sol-Gel Sci. Technol. 2013, 68, 278-283. [CrossRef]

35. Ballato, J.; Riman, R.E.; Snitzer, E. Sol-gel synthesis of fluoride optical materials for planar integrated photonic applications. J. Non-Cryst. Solids 1997, 213-214, 126-136. [CrossRef]

36. Kumar, G.A.; Riman, R.; Snitzer, E. Solution synthesis and spectroscopic characterization of high $\mathrm{Er}^{3+} \mathrm{content}^{\mathrm{s}}$ $\mathrm{LaF}_{3}$ for broadband $1.5 \mu \mathrm{m}$ amplification. J. Appl. Phys. 2004, 95, 40-44. [CrossRef]

37. Hench, L.L.; West, J.K. The sol-gel process. Chem. Rev. 1990, 90, 33-72. [CrossRef]

38. Gorni, G.; Velázquez, J.J.; Mosa, J.; Balda, R.; Fernández, J.; Durán, A.; Castro, Y. Transparent Glass-Ceramics Produced by Sol-Gel: A Suitable Alternative for Photonic Materials. Materials 2018, 11, 212. [CrossRef]

39. Rubio-Zuazo, J.; Ferrer, P.; López, A.; Gutiérrez-León, A.; Silva, I.; Castro, G.R. Nuclear Instruments and Methods in Physics Research A The multipurpose X-ray diffraction end-station of the BM25B-SpLine synchrotron beamline at the ESRF. Nucl. Inst. Methods Phys. Res. A 2013, 716, 23-28. [CrossRef]

40. Rodríguez-Carvajal, J. Recent advances in magnetic structure determination by neutron powder diffraction. Phys. B Condens. Matter 1993, 192, 55-69. [CrossRef]

41. Ravel, B.; Newville, M. ATHENA, ARTEMIS, HEPHAESTUS: Data analysis for X-ray absorption spectroscopy using IFEFFIT. J. Synchrotron Radiat. 2005, 12, 537-541. [CrossRef] [PubMed]

42. Innocenzi, P.; Abdirashid, M.O.; Guglielmi, M. Structure and properties of sol-gel coatings from methyltriethoxysilane and tetraethoxysilane. J. Sol-Gel Sci. Technol. 1994, 3, 47-55. [CrossRef]

43. Ma, Y.; Lee, H.R.; Tsuru, T. Study on Preparation and Hydrophobicity of MTES Derived Silica Sol and Gel. Adv. Mater. Res. 2012, 535-537, 2563-2566. [CrossRef]

44. Gorni, G.; Pascual, M.J.; Caballero, A.; Velázquez, J.J.; Mosa, J.; Castro, Y.; Durán, A. Crystallization mechanism in sol-gel oxyfluoride glass-ceramics. J. Non-Cryst. Solids 2018, 501, 145-152. [CrossRef] 
45. Yu, Y.; Chen, D.; Cheng, Y.; Wang, Y.; Hu, Z.; Bao, F. Investigation on crystallization and influence of $\mathrm{Nd}^{3+}$ doping of transparent oxyfluoride glass-ceramics. J. Eur. Ceram. Soc. 2006, 26, 2761-2767. [CrossRef]

46. Bhattacharyya, S.; Bocker, C.; Heil, T.; Jinschek, R.; Höche, T.; Rüssel, C.; Kohl, H. Experimental Evidence of Self-Limited Growth of Nanocrystals in Glass Experimental Evidence of Self-Limited Growth of Nanocrystals in Glass. Nano Lett. 2009, 9, 2493-2496. [CrossRef]

47. Bhattacharyya, S.; Höche, T.; Hemono, N.; Pascual, M.J.; van Aken, P.A. Nano-crystallization in $\mathrm{LaF}_{3}-\mathrm{Na}_{2} \mathrm{O}-\mathrm{Al}_{2} \mathrm{O}_{3}-\mathrm{SiO}_{2}$ glass. J. Cryst. Growth 2009, 311, 4350-4355. [CrossRef]

48. de Pablos-Martín, A.; Muñoz, F.; Mather, G.C.; Patzig, C.; Bhattacharyya, S.; Jinschek, J.R.; Höche, T.; Durán, A.; Pascual, M.J. KLaF 4 nanocrystallization in oxyfluoride glass-ceramics. CrystEngComm 2013, 15, 10323-10332. [CrossRef]

49. de Pablos-Martín, A.; Hémono, N.; Mather, G.C.; Bhattacharyya, S.; Höche, T.; Bornhöft, H.; Deubener, J.; Muñoz, F.; Durán, A.; Pascual, M.J. Crystallization kinetics of $\mathrm{LaF}_{3}$ nanocrystals in an oxyfluoride glass. J. Am. Ceram. Soc. 2011, 94, 2420-2428. [CrossRef]

50. Velázquez, J.J.; Mosa, J.; Gorni, G.; Balda, R.; Fernández, J.; Pascual, L.; Durán, A.; Castro, Y. Transparent $\mathrm{SiO}_{2}-\mathrm{GdF}_{3}$ sol-gel nano-glass ceramics for optical applications. J. Sol-Gel Sci. Technol. 2019, 89, 322-332. [CrossRef]

51. Jia, Y.Q. Crystal radii and effective ionic radii of the rare earth ions. J. Solid State Chem. 1991, 95, $184-187$. [CrossRef]

52. Gorni, G.; Balda, R.; Fernández, J.; Velázquez, J.J.; Pascual, L.; Mosa, J.; Durán, A.; Castro, Y. 80SiO $2-20 \mathrm{LaF}_{3}$ oxyfluoride glass ceramic coatings doped with $\mathrm{Nd}^{3+}$ for optical applications. Int. J. Appl. Glass Sci. 2018, 9, 208-217. [CrossRef]

53. Li, F.; Li, C.; Liu, X.; Bai, T.; Dong, W.; Zhang, X.; Shi, Z.; Feng, S. Microwave-assisted synthesis and up-down conversion luminescent properties of multicolor hydrophilic $\mathrm{LaF}_{3}: \mathrm{Ln}^{3+}$ nanocrystals. Dalt. Trans. 2013, 42, 2015-2022. [CrossRef]

54. Agarwal, B.K.; Verma, L.P. A rule for chemical shifts of X-ray absorption edges. J. Phys. C Solid State Phys. 1970, 3, 535-537. [CrossRef]

55. Choi, Y.G. Covalence of chemical bonds and white-line intensity of an L3-edge X-ray absorption near-edge structure of rare earth elements embedded in glass. Met. Mater. Int. 2009, 15, 993-999. [CrossRef]

56. Figueroa, A.I.; van der Laan, G.; Harrison, S.E.; Cibin, G.; Hesjedal, T. Oxidation Effects in Rare Earth Doped Topological Insulator Thin Films. Sci. Rep. 2016, 6, 22935. [CrossRef] [PubMed]

57. de Pablos-Martín, A.; García, M.A.; Muñoz-Noval, A.; Castro, G.R.; Pascual, M.J.; Durán, A. Analysis of the distribution of $\mathrm{Tm}^{3+}$ ions in $\mathrm{LaF}_{3}$ containing transparent glass-ceramics through $\mathrm{X}$-ray absorption spectroscopy. J. Non-Cryst. Solids 2014, 384, 83-87. [CrossRef]

58. Dantelle, G.; Mortier, M.; Vivien, D. EPR and optical studies of erbium-doped $\beta-\mathrm{PbF}_{2}$ single-crystals and nanocrystals in transparent glass-ceramics. Phys. Chem. Chem. Phys. 2007, 9, 5591-5598. [CrossRef] [PubMed]

59. Baker, J.M.; Rubins, R.S. Electron Spin Resonance in Two Groups of Lanthanon Salts. Proc. Phys. Soc. 1961, 78, 1353-1360. [CrossRef]

60. Schulz, M.B.; Jefries, C.D. Spin-Lattice Relaxation of Rare-Earth Ions in LaF . Phys. Rev. 1966, 149, $270-288$. [CrossRef]

61. Budoyo, R.P.; Kakuyanagi, K.; Toida, H.; Matsuzaki, Y.; Munro, W.J.; Yamaguchi, H.; Saito, S. Electron paramagnetic resonance spectroscopy of $\mathrm{Er}^{3+}: \mathrm{Y}_{2} \mathrm{SiO}_{5}$ using a Josephson bifurcation amplifier: Observation of hyperfine and quadrupole structures. Phys. Rev. Mater. 2018, 2, 11403. [CrossRef]

62. Yang, S.; Evans, S.M.; Halliburton, L.E.; Slack, G.A.; Schujman, S.B.; Morgan, K.E.; Bondokov, R.T.; Mueller, G.; Yang, S.; Evans, S.M.; et al. Electron paramagnetic resonance of ions in aluminum nitride Electron paramagnetic resonance of $\mathrm{Er}^{3+}$ ions in aluminum nitride. J. Appl. Phys. 2009, 105, 23714-23715. [CrossRef]

(C) 2019 by the authors. Licensee MDPI, Basel, Switzerland. This article is an open access article distributed under the terms and conditions of the Creative Commons Attribution (CC BY) license (http:/ / creativecommons.org/licenses/by/4.0/). 